\title{
Background and Activities of the Samsung Ombudsperson Commission in Korea
}

\author{
Cheolsoo Lee', Seong-Kyu Kang ${ }^{2}$, Hyunwook Kim³ ${ }^{3}$ Inhee Kim ${ }^{4}$ \\ ${ }^{1}$ Seoul National University School of Law, Seoul, Korea; ${ }^{2}$ Department of Occupational and Environmental Medicine, Gachon University College of \\ Medicine, Incheon, Korea; ${ }^{3}$ Department of Preventive Medicine, College of Medicine, The Catholic University of Korea, Seoul, Korea; ${ }^{4}$ Expert Advisor \\ at Seoul National University Human Rights Center, Attorney at Law, Seoul, Korea
}

Objectives: The Samsung Ombudsperson Commission was launched as an independent third-party institution following an agreement among Samsung Electronics, Supporters for Health and Right of People in Semiconductor Industry (Banolim in Korean, an independent NGO), and the Family Compensation Committee, in accordance with the industry accident prevention measure required by the settlement committee to address the issues related to employees who allegedly died from leukemia and other diseases as a result of working at Samsung's semiconductor production facilities.

Methods: The Commission has carried out a comprehensive range of activities to review and evaluate the status of the company's occupational accidents management system, as well as occupational safety and health risk management within its facilities.

Results: Based on the results of this review, termed a comprehensive diagnosis, the Commission presented action plans for improvement to strengthen the company's existing safety and health management system and to effectively address uncertain risks in this area going forward.

Conclusions: The Commission will monitor the execution of the suggested tasks and provide advice and guidance to ensure that Samsung's semiconductor and liquid crystal display production lines are safer.

Key words: Samsung Ombudsperson Commission, Leukemia, Occupational disease, Samsung Electronics, Semiconductors

\section{INTRODUCTION}

In March 2007, Yu-mi Hwang, a former worker at a Samsung Electronics plant in Giheung, died of acute myelocytic leukemia. In November of the same year, other Samsung employees suffering from similar conditions, Hwang's bereaved family members, and civil activists jointly formed a group called the Joint

Received: February 13, 2019 Accepted: July 3, 2019

Corresponding author: Cheolsoo Lee, PhD

Seoul National University School of Law, 1 Gwanak-ro, Gwanak-gu,

Seoul 08826, Korea

E-mail: charles2@snu.ac.kr

This is an Open Access article distributed under the terms of the Creative Commons Attribution Non-Commercial License (http://creativecommons.org/licenses/by$\mathrm{nc} / 4.0 /$ ) which permits unrestricted non-commercial use, distribution, and reproduction in any medium, provided the original work is properly cited.
Action Committee for Learning the Facts about the Outbreak of Leukemia at Samsung Semiconductors and for securing the Basic Rights of Labor. The group later changed its name to Supporters for Health and Right of People in Semiconductor Industry (SHARPs, Banolim in Korean). Hwang's family members and the company's employees applied to the Korea Workers' Compensation and Welfare Service for workers' compensation insurance, claiming that leukemia and other incurable diseases should be acknowledged as a type of occupational diseases. The claim was denied based on the results of the Occupational Safety and Health Research Institute (OSHRI)'s epidemiological investigation result, which concluded that "there was an increased risk of lympho-hematopoietic diseases, but it was not statistically significant." In 2010, the group filed an administrative lawsuit in the hope of overturning the denial, and in 
this lawsuit, the court ruled in favor of some of the cases [1] (Appendix 1). In the meanwhile, three Korean semiconductor makers conducted self-assessments on occupational health risks in 2009, following advice from the Ministry of Employment and Labor [2]. OSHRI's epidemiological investigations of Korea's six semiconductor companies to make up for statistical loopholes in the previous study is still ongoing [3]. The final result released in May, 2019 that "there was an increased risk of lympho-hematopoietic diseases, however, the association between work and diseases was not confirmed" [4].

Since 2013, Samsung Electronics, SHARPs, and the Family Committee for Compensation over Leukemia Issue have made efforts to reach a settlement that can put an end to the longrunning leukemia issue, leading to the establishment of a mediation committee to address the issues on the putative workplace outbreak of leukemia and other diseases at Samsung Electronics facilities. The committee released a settlement ruling in July 2015, requiring apology, compensation, and prevention measures. The three parties reached an agreement in January 2016, regarding prevention measures, which led to the establishment of the Samsung Ombudsperson Commission [5] (Appendix 2).

This article describes how this settlement laid the foundations for the formation of the Ombudsperson Commission and summarizes the details of the comprehensive evaluation activities, referred to as a comprehensive diagnosis, as well as the results.

\section{METHODS}

\section{The History and Foundation of the Ombudsperson Commission}

The Samsung Ombudsperson Commission was launched based on a three-party agreement about strategies for occupational disease prevention. The three-party settlement agreement served as the foundation for establishment and direction of activities. The main features of the agreement are as follows:

Article 1 of the agreement describes the goal of the prevention measures: Samsung should devise a "complete system for a healthy and safe workplace." In other words, the company should look for ways to improve the organizational culture and establish an effective channel to communicate with independent institutions that work for the public interest, as well as a detailed plan to prevent occupational diseases in the fu- ture. To this end, the agreement called for reinforcement of the company's internal occupational health management system, which is to be reviewed and confirmed by the Ombudsperson Commission, an independent organization.

The Commission was chaired by Prof. Cheolsoo Lee of Seoul National University School of Law and its leadership included two other members: the late Prof. Hyun-Sul Lim of Dongguk University College of Medicine and Prof. Hyunwook Kim of College of Medicine, The Catholic University of Korea. After Prof. Lim passed away in 2018, Prof. Seong-Kyu Kang of Gachon University College of Medicine assumed in August of the same year.

The Commission's main roles were to conduct a comprehensive diagnosis of the current status of these issues and to monitor the execution of improvement measures. The diagnostic process included reviewing and evaluating data submitted by Samsung regarding the operational status of its internal accident management system and occupational health management, as well as publicizing reports on suggested improvements when needed by requesting further data and/or onsite inspections (Article 3, Paragraph 3 of the Agreement). The specific areas subject to the Commission's diagnosis were: (1) An evaluation of harmful factors in the workplace environment and improvement plans (evaluation of chemical substance management and improvement plans, evaluation of the workplace environment and improvement plans, construction of a job-exposure matrix, etc.); (2) Conducting an epidemiological study on the health effects of the workplace environment (epidemiological investigations of former and current workers, in-depth studies of groups with a high suspicion of occupational disease, and in-depth interviews with employees); (3) Inspection of the current comprehensive health management system and improvement plans (health management and enhancement activities); (4) Inspections and studies to prevent occupational accidents and diseases (studying academic papers and policies regarding occupational safety and health standards for chemical substances, studying cases in other countries, releasing research papers, and conducting promotional activities); and (5) Advising and/or suggesting actions by Samsung through reviewing and advising Samsung about confidential information and data regarding chemical substances (any and all activities that have to do with establishment, revision, and enforcement of detailed regulations on sharing information about harmful chemical substances used in Samsung's semiconductor and liquid crystal display [LCD] 
facilities and trade secrets).

The monitoring activity mainly included an annual inspection of Samsung's execution of the improvement plans throughout the effective period, as well as suggesting and/or advising any additional improvements as needed after requesting additional data or onsite inspections, and reporting the results thereof.

The leadership of the Commission included a chair and professors of occupational medicine and industrial hygiene, with five sub-committees by ten professors organized into two departments to perform a comprehensive diagnosis. Department 1 consisted of three sub-committees with eight experts each: the Physical and Chemical Substances Team, the Health Effects Research Team, and the Occupational Health System Improvement Team. Department 2 consisted of two sub-committees with two experts each: the Research and Investigation Team and the Regulation Review Team. The comprehensive diagnosis was performed by each expert with an assigned role under supervision of the Ombudsperson leadership. In June 2016 and September 2016, the Commission and the five teams selected topics for each one and assembled a diagnosis group of 41 experts including the Ombudsperson. In November 2016, the Commission signed a contract with Samsung Electronics and Samsung Display mediated by the Seoul National University R\&DB Foundation and carried out investigations into Samsung's semiconductor and LCD facilities, including the Giheung, Hwasung, Onyang, and Asan locations, between November 2016 and December 2017.

The Commission disclosed the results of their activities at a press conference held on April 25, 2018, to ensure transparency of the diagnosis [6]. The "Comprehensive Diagnosis Report" was shared with the public in August 2018, after making revisions based on opinions received from the stakeholders.

\section{Ethics Statement}

This comprehensive diagnosis project itself isn't human subject research, but some specific subjects performed by each expert with an assigned role under supervision of the Ombudsperson leadership were approved by the institutional review board from their affiliation institute.

\section{RESULTS}

The key findings of the report on the comprehensive diagnosis are described below.
The most recent 3 years of work environment data from Samsung regarding physical and chemical substances and radiation showed encouraging results, as $79.9 \%$ of the substances investigated were non-existent at the Giheung and Hwasung plants, $71.6 \%$ were not found at the Onyang location, and $73.0 \%$ were not present at Asan. Among the substances that were detected, none were present at levels exceeding $10 \%$ of the occupational exposure levels (OELs) of Korea. The team looked for 25 key chemicals selected based on their relevance for trade secrets, quantity, and toxicity in 54 bulk samples of photoresistors used during the photographic process. Sixteen of the 25 chemicals, including benzene and ethylene glycol ethers, were determined to be non-existent and nine chemicals, including toluene and o-cresol, were found at negligible levels, unlikely to be harmful even with long-term exposure. Most of the chemicals were not detected in tests for preventive maintenance workers, while the detected substances were all under $10 \%$ of the OELs. Exposure to electromagnetic fields was also lower than $10 \%$ of the recommended level. A status of radiation equipment management and the risk of exposure to radiation of workers were both within the minimum safety requirements of the Nuclear Safety Act. The expected exposure rate of employees working near radiation equipment was on average $0.2 \mathrm{mSv}$, referred to $1 \mathrm{mSv}$ for the general public [7].

A systemic review and meta-analysis were performed of the relevant literature to obtain insights into the correlations between the occurrence of cancer and other major diseases and occupation among semiconductor workers. Occupational correlations between the onset of leukemia, non-Hodgkin lymphoma, brain tumor, and breast cancer and the workplace environment in the semiconductor industry were not verifiable with currently available resources. Focus group interviews of former and current semiconductor workers suggested potential exposure to chemicals, noises, and odors in old procedures that are different from those currently used, but there was no way to confirm this at facilities that had already been shut down. It was only confirmed that the current process has been automated to a great extent and that workers are no longer directly exposed to chemical substances or harsh environments. The levels of biological exposure among current workers to harmful chemicals such as benzene and arsenic were largely similar to the levels found among the general public, according to biomarker test results [7]. This suggests that the current environment poses almost no potential health risk. 
Investigations of the company's occupational health management system confirmed that an internal health management team was in place and that the company provided support for expert consultations, guidance for the industrial accident compensation insurance application process, and a service desk for compensation-eligible diseases, in case an employee develops a possible occupational disease.

Studies of future policies for preventive measures confirmed that the company needs policies to prevent potential risks. A new risk management system using big-data-based artificial intelligence was suggested as an alternative. Additionally, a dedicated team is needed to enhance communication between stakeholders within and outside the company regarding health, safety, and environment issues, thereby improving the credibility of the company [7].

Investigations into practices of sharing and archiving material safety and health data on harmful chemicals concluded that the company should share all data regarding chemical substances used in their facilities in order to protect workers and ensure their right to know, considering the huge number of chemicals used in the semiconductor and LCD facilities. AIthough semiconductor and LCD technologies and their trade secrets should undoubtedly be protected as key national technology assets, such protection must be kept to a minimum level in order not to compromise workers' health [7].

\section{DISCUSSION}

The results of the comprehensive diagnosis did not demonstrate any occupational correlations with the development of incurable diseases among some of Samsung's semiconductor and LCD manufacturing employees. Improvement plans were proposed to completely rule out any potential risks that are currently unverifiable and to effectively address uncertainties regarding future health management. Core action points of the improvement plan include removing future uncertain risks through continuing enhancement and maintenance of the work environment and chemical substance management practice; conducting long-term follow-up surveys on correlations between jobs and diseases using a job-exposure matrix and cohorts; promoting employees' health by upgrading the existing occupational health program to help workers with lifestyle diseases and to encourage healthy workers to maintain their status quo; introducing a big-data-based risk man-

Table 1. Core action items for improvement

\begin{tabular}{|c|c|c|}
\hline Sub-committee & Category & Details \\
\hline \multirow{6}{*}{$\begin{array}{l}\text { Physical and chemical } \\
\text { substances }\end{array}$} & Work environment data & Continue monitoring the level of exposure in preventive maintenance work \\
\hline & Work environment management & Conduct regular monitoring of recirculated air quality in the clean room \\
\hline & Chemical substance management & Reinforce analysis of major harmful substances \\
\hline & System development & Construct a job-exposure matrix \\
\hline & Training, promotion, communication & Continue education for the risk of chemical substances \\
\hline & Partner support & Enhance safety and health management support for partners \\
\hline \multirow[t]{2}{*}{ Health effects research } & Establish cohorts & Set up prospective cohorts for semiconductor and LCD workers \\
\hline & Biological exposure evaluation & Conduct a biological exposure study \\
\hline \multirow{4}{*}{$\begin{array}{l}\text { Employee occupational } \\
\text { health system } \\
\text { improvements }\end{array}$} & Health promotion programs & Introduce a customized health promotion program for employees with chronic diseases \\
\hline & Health management system & Come up with mid- to long-term plans for health promotion activities \\
\hline & System development & Introduce a mobile healthcare system \\
\hline & Training, promotion, communication & Strengthen communication among health promotion departments \\
\hline \multirow[t]{3}{*}{ Research and investigation } & Chemical substance management & Conduct a quantitative study of chemical substance uncertainty risks \\
\hline & System development & $\begin{array}{l}\text { Establish a health, safety and environment management system using artificial } \\
\text { intelligence analyses of big data }\end{array}$ \\
\hline & Training, promotion, communication & $\begin{array}{l}\text { Assemble a dedicated communications team for issues related to health, safety, and the } \\
\text { environment }\end{array}$ \\
\hline \multirow[t]{3}{*}{ Regulation review } & Data sharing & Share a list of chemicals used \\
\hline & Training, promotion, communication & $\begin{array}{l}\text { Install equipment that can confirm whether material safety data sheet guidelines are } \\
\text { followed }\end{array}$ \\
\hline & Safety health management system & Expand archives (including the duration of storage) for employees' health data \\
\hline
\end{tabular}

LCD, liquid crystal display. 
agement system; enhancing risk-related communication between stakeholders within and outside of the company; and sharing chemical data using in facilities to secure workers' right to know. The full list is presented in Table 1.

The Ombudsperson Commission will examine Samsung's implementation of these core action plans to ensure that the company's semiconductor and LCD lines are safer and healthier.

\section{SUPPLEMENTAL MATERIALS}

Korean version is available at https://doi.org/10.3961/jpmph . 19.033.

\section{CONFLICT OF INTEREST}

The authors have no conflicts of interest associated with the material presented in this paper.

\section{ACKNOWLEDGEMENTS}

We thanks to all experts who participated in this comprehensive diagnosis project, and especially thanks to the dedication of the late Prof. Hyun-Sul Lim (Dongguk University College of Medicine) for the commission.

Samsung Ombudsperson Commission is financially supported by Samsung Electronics and Samsung Display through Seoul National University R\&DB Foundation, according to Article 3, Paragraph 6 of the three parties' (Samsung Electronics, SHARPs, and the Family Committee for Compensation over Leukemia Issue) settlement agreement regarding prevention measures in January 2016.

\section{AUTHOR CONTRIBUTIONS}

Conceptualization: CL, SKK, HK. Data curation: CL, SKK, HK. Formal analysis: $\mathrm{CL}$, SKK, HK. Funding acquisition: CL. Methodology: CL, SKK, HK. Project administration: CL. Visualization: None. Writing - original draft: IK. Writing - review \& editing: $\mathrm{CL}$, SKK, HK.

\section{ORCID}

Cheolsoo Lee https://orcid.org/0000-0002-0999-8116

Seong-Kyu Kang https://orcid.org/0000-0002-3205-2708
Hyunwook Kim https://orcid.org/0000-0002-1861-2529

Inhee Kim https://orcid.org/0000-0002-6525-332X

\section{REFERENCES}

1. Park S. Acknowledgement of occupational accident for the Samsung Electronics leukemia case. Monthly Labor Law; 2016 Dec 30 [cited 2019 Feb 13]. Available from: http://www.worklaw. co.kr/view/view.asp?in_cate $=1010 \& g o p a g e=1 \& b i \_p i d x=$ 26048\&sPrm =Search_Text \$\%BB\%EF\%BC\%BA\%CO\%FC\% C0\%DA\%20\%B9\%E9\%C7\%F7\%BA\%B4\%20\%BB\%E7\%B0\% C7\%C0\%C7@@keyword\$\$\%BB\%EF\%BC\%BA\%C0\%FC\%CO\% DA\%20\%B9\%E9\%C7\%F7\%BA\%B4\%20\%BB\%E7\%B0\%C7\% C0\%C7 (Korean).

2. Ministry of Employment and Labor. Industry health risk assessment for semiconductor manufacturers; 2009 Jun 9 [cited 2019 Feb 13]. Available from: https://www.moel.go.kr/news/ enews/report/enewsView.do;jsessionid =UIDbFhAPa02gICjH VXM1JDLNaX8CtGwxkCTK2gR4itels9PIMrflltV456wEJ60p. moel_was_outside_servlet_www2?news_seq $=158$ (Korean, author's translation).

3. Occupational Safety and Health Research Institute. A study on non-Hodgkin lymphoma patient-control group research design and viability among semiconductor industry workers in 2015; 2018 Jan 10 [cited 2019 Feb 13]. Available from: https:// oshri.kosha.or.kr/main?urlCode =T1\%7C\%7C12081\%7C366\% 7C366\%7C374\%7C12081\%7C\%7C/cms/board/board/Board. jsp\&communityKey $=$ B1 182\&site_id $=3 \&$ tabld $=$ \&community Key $=$ B1 182\&pageNum $=1$ \&pageSize $=10 \&$ act $=$ VIEW\&bran ch_session $=\& o n l y \_r e p l y=\&$ mbo_mother_page $=/$ main $\&$ board_table_name $=$ WCM_BOARD_B1 182\&sort_type $=$ DESC\& sort_column $=\&$ searchType $=$ ALL\&searchWord $=\&$ boardld $=6$ (Korean, author's translation).

4. Occupational Safety and Health Research Institute. Epidemiological survey on workers health status in semiconductor manufacturing - focusing on cancer; 2015 May 22 [cited 2019 Jul 18]. Available from: https://oshri.kosha.or.kr/main?urlCode $=T 1|| 12087|366| 366|374| 12087|| / \mathrm{cms} /$ board $/$ board $/$ Board . jsp\&communityKey $=$ B1 184\&site_id $=3 \&$ tabld $=$ \&community Key $=$ B1 184\&pageNum $=1$ \&pageSize $=10 \&$ act $=$ VIEW\&bran ch_session $=\& o n l y \_r e p l y=\&$ mbo_mother_page $=/$ main $\&$ board_table_name $=$ WCM_BOARD_B1184\&sort_type $=$ DESC\& sort_column $=\&$ searchType $=$ ALL\&searchWord $=\&$ boardld $=2$ (Korean, author's translation).

5. Ju HJ. Samsung to launch an Ombudsperson Commission to 
prevent occupational diseases. Seoul Shinmun; 2016 Jan 13 [2019 Feb 13]. Available from: http://www.seoul.co.kr/news/ newsView.php?id $=20160113005023 \# c s i d x 94 e 880592 c 5 d 21$ 4a2e1251aebdc5e35 (Korean).

6. Kim JY. Samsung Ombudsperson Commission to announce comprehensive diagnosis results for leukemia cases on April
25. Aju Business Daily; 2018 Apr 23 [cited 2019 Feb 13]. Available from: https://www.ajunews.com/view/2018042316054 8280 (Korean).

7. Samsung Ombudsperson Commission, Comprehensive diagnosis report by the Samsung Ombudsperson Commission. Seoul: Samsung Ombudsperson Commission; 2018 (Korean). 


\section{Journal of}

Appendix 1. Court rulings on the 2010 lawsuit

Five representatives of the bereaved family members and employees filed a lawsuit requesting that the previous denial of compensation for loss and funeral expenses be overturned. Two of the five plaintiffs won at the first trial (Seoul Administrative Court Order 2010Guhap1149 Dated June 23, 2011) as well as at the upper court (Seoul High Court Order 2011Nu23995 Dated August 21, 2014). Korea Workers' Compensation and Welfare Service did not take the case to a third trial, while the remaining three plaintiffs lost at the Supreme Court trial (Supreme Court Order 2014Du12185 Dated August 30, 2016).

The Supreme Court Order is available at the following link:

http://law.go.kr/preclnfoP.do?mode =0\&precSeq =184003

Appendix 2. Final settlement agreement regarding compensation and apologies

On November 1, 2018, Samsung Electronics and SHARPs agreed on issues regarding compensation, apologies, prevention of recurrence, and social contributions through a settlement reached under a mediation committee. Samsung Electronics officially apologized as part of the agreement to implement the settlement on November 23, 2018. Compensation will be supervised by an independent committee and Samsung agreed to contribute 50 billion for the prevention of recurrence and related social activities (Settlement agreement by the mediation committee to address issues related to the development of leukemia and other diseases at Samsung electronics semiconductor facilities, November 1, 2018). 